\title{
Preparation and Characterization of P(AN-VAc-PMMT) Nanocomposites and Nanofibers
}

\author{
Jun Liu, ${ }^{1,2}$ Yuguo Zhuo, ${ }^{1,2}$ Qingshan Li, ${ }^{1}$ Wei Hong, ${ }^{3}$ and Guangzhong Xing ${ }^{1}$ \\ ${ }^{1}$ National Key Laboratory of Metastable Materials Preparation Technology and Science, Yanshan University, \\ Qinhuangdao 066004, China \\ ${ }^{2}$ Environmental Management College of China, Qinhuangdao 066004, China \\ ${ }^{3}$ People's Republic of China Qinghuangdao Entry-Exit Inspection \& Quarantine Bureau Coal Inspection Technique Center, \\ Qinhuangdao 066003, China \\ Correspondence should be addressed to Qingshan Li; qsli@ysu.edu.cn
}

Received 25 March 2014; Revised 26 May 2014; Accepted 27 May 2014; Published 9 June 2014

Academic Editor: Bing Wu

Copyright (C) 2014 Jun Liu et al. This is an open access article distributed under the Creative Commons Attribution License, which permits unrestricted use, distribution, and reproduction in any medium, provided the original work is properly cited.

$\mathrm{P}(\mathrm{AN}-\mathrm{VAc}-\mathrm{PMMT})$ nanocomposites were prepared using in situ emulsion polymerization and further confirmed by FTIR. A polymerizable quaternary ammonium ion monomer was used to modify montmorillonite. XRD testing showed that the quaternary ammonium ion was successfully intercalated into the montmorillonite chip layer. This is the first paper to discuss an investigation of $\mathrm{P}(\mathrm{AN}-\mathrm{VAc}-\mathrm{PMMT})$ nanofiber morphology using SEM. The fibers were prepared through electrospinning.

\section{Introduction}

In recent years, a significant amount of work has been carried out on polymer-clay nanocomposites because they show more favorable mechanical properties than pure polymers and conventional inorganic-polymer composites [1-3]. The most common approaches [4] to achieving exfoliated nanocomposite structures are modification of the chemistry of the clay surface from hydrophilic to organophilic, which improves compatibility with the host polymer $[5,6]$ matrix, and special processing techniques, such as in situ polymerization, high shear solution blending, and melt blending $[7,8]$.

Electrospinning is an effective method for the production of polymeric fibers [9] with diameters ranging from tens of nanometers to microns. The feasibility of incorporating nanometer-sized particulates into fibers has made this process even more attractive in the production of composite fibers.

The purpose of this project was to improve the thermal properties of PAN-based fibers via electrospinning. Specifically, this paper describes the formation of electrospun fibers from solutions of poly (AN-co-VAc) copolymers and dispersions of their layered-silicate nanocomposites. Fibers have also been formed under the same conditions. The nanocomposites were prepared using in situ emulsion polymerization to enhance the dispersion and exfoliation of clay in the polymer matrix. The polymerized nanocomposites were then dispersed into solutions of dimethylformamide (DMF), from which fibers were electrospun. The morphology and thermal properties of the electrospun fibers from the copolymer and nanocomposite solutions were characterized.

\section{Experiments}

2.1. MSDQA (Methyl Styrene Dodecyl Quaternary Ammonium) Preparation. A certain amount of acetone, chloromethyl styrene, and dodecyl dimethyl amine was added to a $250 \mathrm{~mL}$ three-neck bottle equipped with a stirrer, reflux condenser, and thermometer. It was heated until the acetone was refluxed. A yellow emulsion was produced after 2 hours. The product was precipitated by $n$-heptane and then washed with 


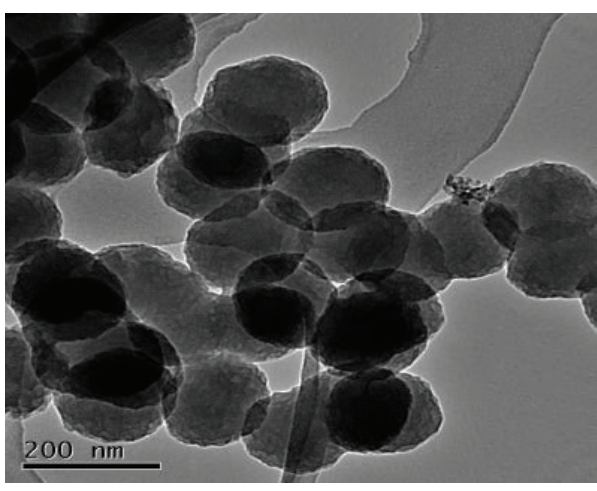

(a)

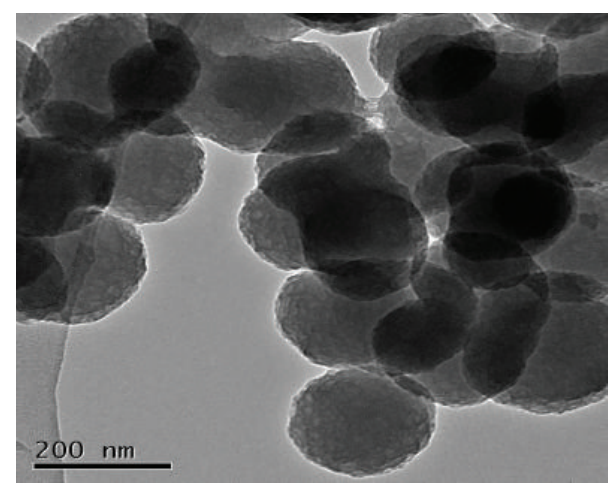

(b)

Figure 1: TEM of P(AN-VAc-PMMT) ((a) 2\%, (b) 5\%).

acetone three times. After centrifugation, the sediment was washed with deionized water, dried in vacuum at $60^{\circ} \mathrm{C}$ for 24 hours, and ground into fine powder.

One gram of Na-MMT was dispersed in $30 \mathrm{~mL}$ of distilled water with vigorous stirring for 0.5 hours at room temperature. Three-tenths of a gram of methyl styrene dodecyl quaternary ammonium was dissolved in $20 \mathrm{~mL}$ of distilled water. The two solutions were mixed under nitrogen and kept at $80^{\circ} \mathrm{C}$ with stirring at $800 \mathrm{rpm}$ for 3 hours. After centrifugation, the sediment was washed with deionized water, dried in a vacuum at $80^{\circ} \mathrm{C}$ for 24 hours, and ground to a fine powder.

2.2. $P(A N-V A c-P M M T)$ Nanocomposite Preparation. The $\mathrm{P}(\mathrm{AN}-\mathrm{co}-\mathrm{VAc})$ copolymers containing $10 \mathrm{wt} \% \mathrm{VAc}$ and layered-silicate nanocomposites with the same nominal compositions were prepared individually via emulsion polymerization.

Details follow: a given weight of PMMT was dispersed in admixture of $9 \mathrm{~g}$ acrylonitrile (AN) and $1 \mathrm{~g}$ vinyl acetate (VAc). The solution was surged ultrasonically for 30 minutes when the ultrasonic frequency was $400 \mathrm{KHz}$ and ultrasonic power was $250 \mathrm{~W}$. $90 \mathrm{~mL}$ deionized water and $0.2 \mathrm{~g}$ sodium dodecyl benzene sulfonate (SDBS) were placed in a threeneck bottle with a battle stirrer, a reflux condenser, and a thermometer. The solution was mixed thoroughly and then added to a PMMT and polymerizable quaternary ammonium ion monomer mixture while being continuously mixed by ultrasonic. When the temperature reached $70^{\circ} \mathrm{C}$, the solution of $\mathrm{K}_{2} \mathrm{~S}_{2} \mathrm{O}_{8}$ was added to the three-neck bottle and allowed to react for about 2 hours. Then it was swilled into beakers and various $13 \mathrm{wt} \% \mathrm{NaCl}$ solutions were added to the beakers to precipitate the product. After centrifugation, the sediment was washed with deionized water, dried in a vacuum at $70^{\circ} \mathrm{C}$ for 24 hours, and ground to a fine powder.

\section{Results and Discussion}

3.1. Characterization of Materials. $\mathrm{P}(\mathrm{AN}-\mathrm{VAc}-\mathrm{PMMT})$ composites prepared by in situ emulsion polymerization presented as nanometer microspheres of about $150 \mathrm{~nm}$ in size (Figure 1). When montmorillonite content was below $5 \%$, the surface morphology of the composite microspheres appeared clear because long chains of polymers curl naturally.

The spectrum contained characteristic absorbance bands of all components. The spectrum of pure MSDQA (Figure 2(a)) shows the peak whose wave numbers are in the region of $1470 \mathrm{~cm}^{-1}$ due to the substance's quaternary ammonium ions. The peaks at $2920 \mathrm{~cm}^{-1}$ and $2850 \mathrm{~cm}^{-1}$ were characteristic of $\mathrm{CH}_{3}$ and $\mathrm{CH}_{2}$ absorption peaks, respectively. The peak at $3450 \mathrm{~cm}^{-1}$ was attributed to the band of water in MSDQA. MSDQA also showed peaks at $1630 \mathrm{~cm}^{-1}$ and $1514 \mathrm{~cm}^{-1}$ due to its phenyl group. Absorbance peaks from $\mathrm{C}-\mathrm{N}$ stretching at $1221 \mathrm{~cm}^{-1}$ confirmed the successful synthesis of MSDQA. Figure 2(b) shows the FTIR spectra of $\mathrm{P}(\mathrm{AN}-\mathrm{VAc}-\mathrm{PMMT})$. The spectrum of $\mathrm{P}(\mathrm{AN}-$ VAc-PMMT) contained characteristic absorbance bands for all components. $\mathrm{C}-\mathrm{H}$ stretching at $2930 \mathrm{~cm}^{-1}, \mathrm{C} \equiv \mathrm{N}$ stretching at $2240 \mathrm{~cm}^{-1}$, and $\mathrm{C}-\mathrm{H}$ bending at $1454 \mathrm{~cm}^{-1}$ are characteristic of $\mathrm{P}(\mathrm{AN}-\mathrm{VAC})$. Absorbance peaks from phenyl groups at $1630 \mathrm{~cm}^{-1}$ and $1514 \mathrm{~cm}^{-1}$ confirmed the presence of MSDQA in the nanocomposite. Absorbance peaks from $\mathrm{O}-\mathrm{H}$ stretching at about $3464 \mathrm{~cm}^{-1}, \mathrm{Si}-\mathrm{O}$ stretching at about $1027 \mathrm{~cm}^{-1}$, and $\mathrm{Si}-\mathrm{O}$ bending at about $520 \mathrm{~cm}^{-1}$ confirmed the presence of PMMT in the nanocomposite. $\mathrm{C}=\mathrm{O}$ stretching at $1740 \mathrm{~cm}^{-1}$ was detected.

As shown in Figure 3, the quaternary ammonium salt was intercalated into the montmorillonite layers on chip by cation exchange, thereby forming composites with the required nanometer-sized spaces. PMMT reflection in the nanocomposite was not observed when PMMT content was below $5 \mathrm{wt} \%$. At the PMMT content of $8 \mathrm{wt} \%$, the PMMT reflection appeared at $2 \theta=1.94^{\circ}$, corresponding to a basal spacing of $4.54 \mathrm{~nm}$. This indicated that the polymer chains were intercalated into the PMMT.

3.2. Analysis of Fiber Morphology. Fiber morphology was characterized using SEM. Figure 4 shows that, as the montmorillonite content increased, the diameters of the $\mathrm{P}(\mathrm{AN}$ VAc-PMMT) fibers did not change significantly and line 


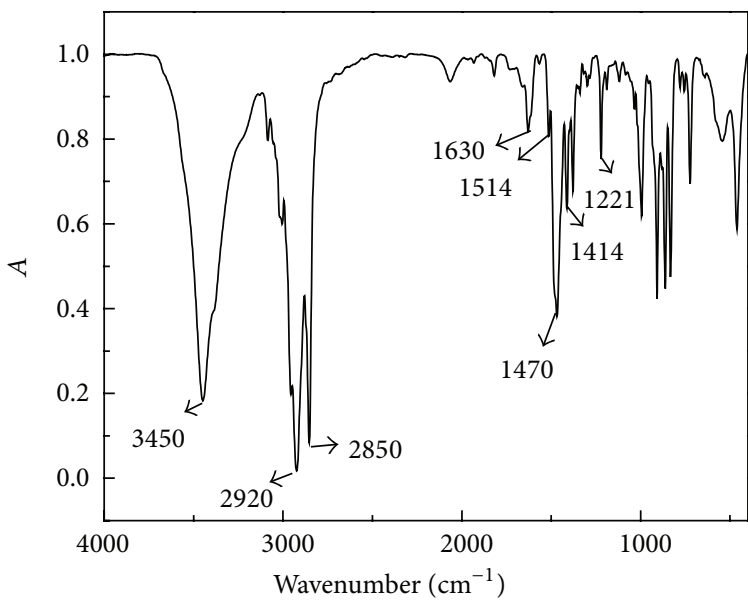

(a)

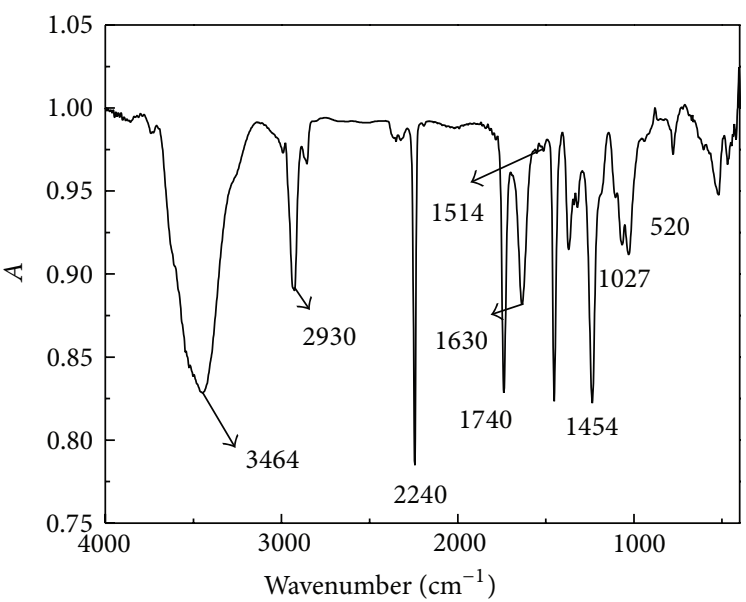

- P(AN-VAc-PMMT)

(b)

FIgURE 2: FTIR spectra of (a) MSDQA and (b) P(AN-VAc-PMMT).

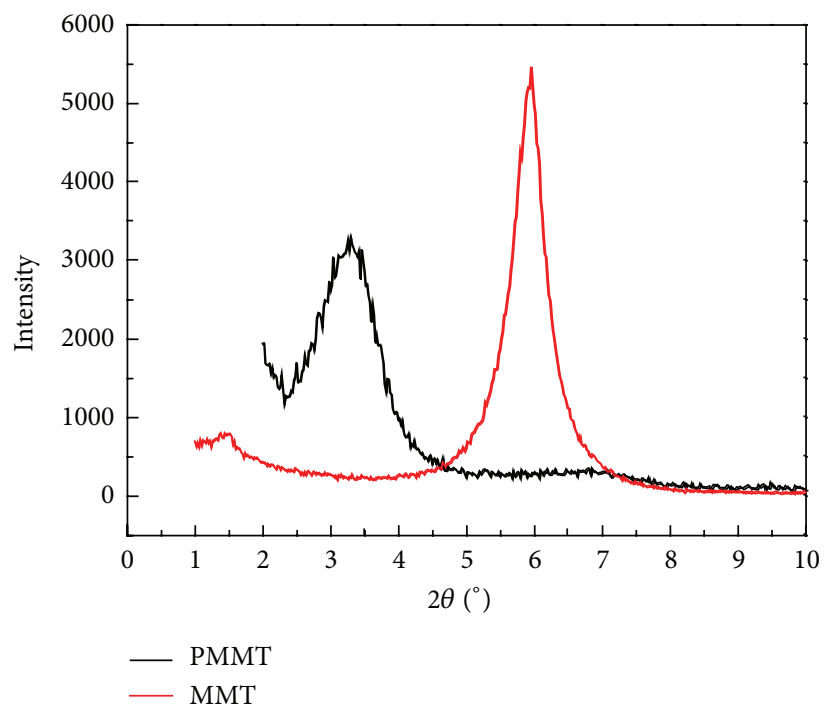

(a)

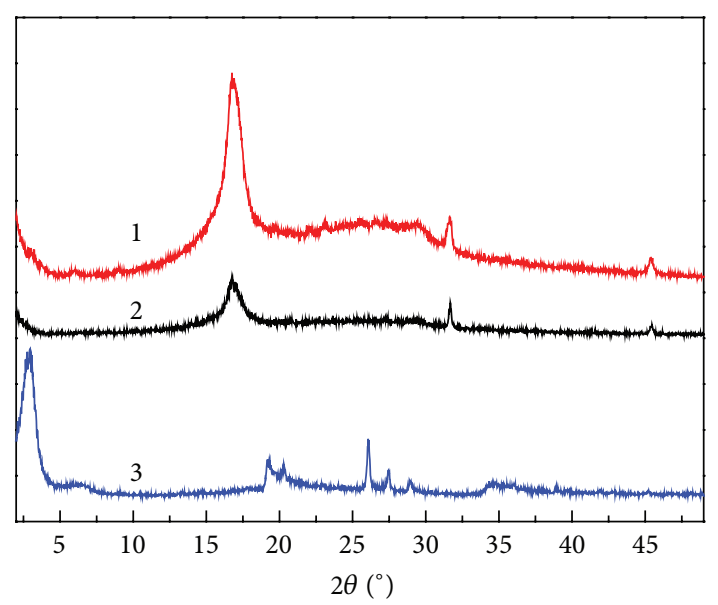

(b)

Figure 3: XRD: (a) Na-MMT and PMMT; (b) 1: the PMMT content $5 \mathrm{wt} \%$, 2: the PMMT content 8 wt\%, and 3: PMMT.

densities were the same. This may have been due to the effect of the molecular weight of composite materials. When montmorillonite was added, the molecular weight of the polymers increased, leading to thickening of the P(AN-VAc-PMMT) fibers. As MMT content increased, the adsorption capacity of MMT to free radicals gradually became preponderant. This caused the molecular weight to decrease slightly. However, this trend was not very obvious. The average diameters of the fibers that were prepared with MMT may have been affected in an inconspicuous way.

Figure 4(a) shows that the electrospun $\mathrm{P}(\mathrm{AN}-\mathrm{VAc})$ fibers contained a certain number of small beads. After montmorillonite was added, the surfaces of the fibers became smooth because the negative charge of the montmorillonite surfaces increased the conductivity of the solution during electrospinning. The polymer chain can be arranged parallel to the surface of the montmorillonite lamellae when the montmorillonite is introduced. In this way, the electrospinnability of $\mathrm{P}(\mathrm{AN}-\mathrm{VAc}-\mathrm{PMMT})$ composite fibers is better than that of $\mathrm{P}(\mathrm{AN}-\mathrm{VAC})$ fibers.

\section{Conclusions}

(1) P(AN-VAc-PMMT) nanocomposites were prepared by the method of emulsion intercalation polymerization. It is a result that $\mathrm{P}(\mathrm{AN}-\mathrm{VAc}-\mathrm{PMMT})$ nanocomposite was synthesized token by FTIR spectra and 


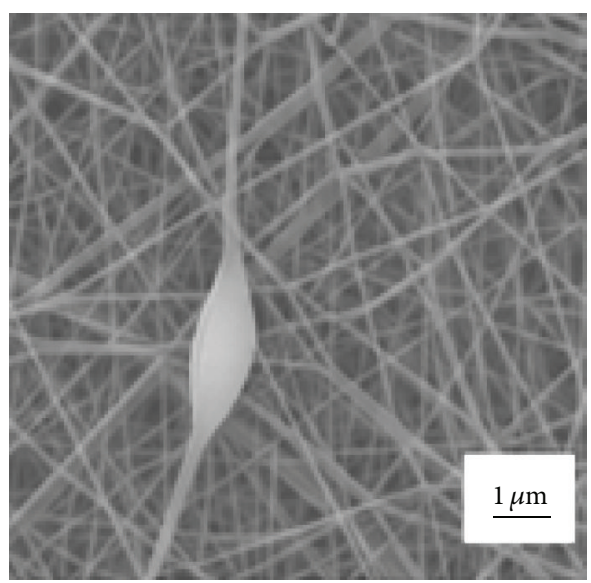

(a)

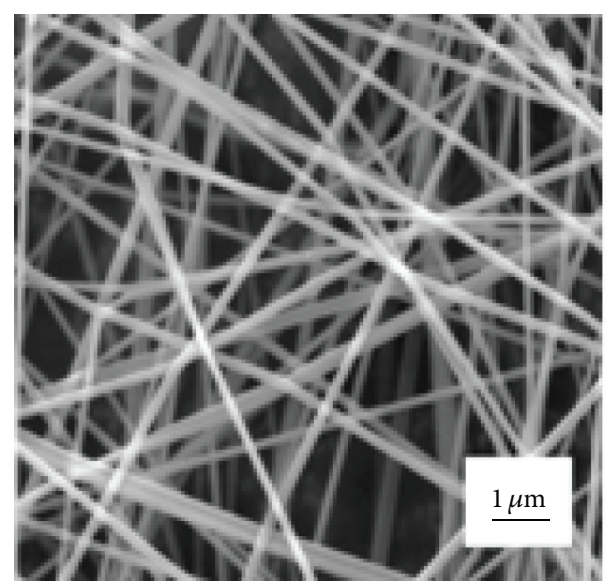

(b)

FIGURE 4: SEM images of P(AN-VAc-PMMT) ((a) 0\%, (b) 2\%) electrospinning fibers processed in a capillary tube with an inner diameter of $0.7 \mathrm{~mm}$ at a voltage of $30 \mathrm{KV}$, a spinning distance of $25 \mathrm{~cm}$, and a speed of $0.5 \mathrm{~mL} / \mathrm{h}$.

the copolymer $\mathrm{P}(\mathrm{AN}-\mathrm{VAc})$ is intercalated into montmorillonite layer by XRD.

(2) $\mathrm{P}(\mathrm{AN}-\mathrm{VAc})$ and $\mathrm{P}(\mathrm{AN}-\mathrm{VAc}-\mathrm{PMMT})$ composites can be made into nanofibers by electrospinning. The electrospinnability of $\mathrm{P}(\mathrm{AN}-\mathrm{VAc})$ fiber composites was found to be better than that of $\mathrm{P}(\mathrm{AN}-\mathrm{VAC})$.

\section{Conflict of Interests}

The authors declare that they have no direct financial relation with the commercial identities mentioned in this paper that might lead to a conflict of interests for any of them regarding the publication of this paper.

\section{Acknowledgments}

This work was supported by the National "Eleventh Five-Year" Technology Support Program Foundation (2006BAD10B08) and the Natural Science Foundation of Hebei Province (E2009000448).

\section{References}

[1] R. S. Sinha and M. Okamoto, "Polymer/layered silicate nanocomposites: a review from preparation to processing," Progress in Polymer Science, vol. 28, no. 11, pp. 1539-1641, 2003.

[2] G. Beyer, "Nanocomposites: a new class of flame retardants for polymers," Plastics, Additives and Compounding, vol. 4, no. 10, pp. 22-28, 2002.

[3] P. Meneghetti and S. Qutubuddin, "Synthesis, thermal properties and applications of polymer-clay nanocomposites," Thermochimica Acta, vol. 442, no. 1-2, pp. 74-77, 2006.

[4] K. Chang, M. Lai, C. Peng et al., "Comparative studies on the corrosion protection effect of DBSA-doped polyaniline prepared from in situ emulsion polymerization in the presence of hydrophilic $\mathrm{Na}^{+}$-MMT and organophilic organo-MMT clay platelets," Electrochimica Acta, vol. 51, no. 26, pp. 5645-5653, 2006.
[5] X. Zhao, K. Urano, and S. Ogasawara, "Adsorption of polyethylene glycol from aqueous solution on montmorillonite clays," Colloid \& Polymer Science, vol. 267, no. 10, pp. 899-906, 1989.

[6] X. H. Liu and Q. J. Wu, "PP/clay nanocomposites prepared by grafting-melt intercalation," Polymer, vol. 42, no. 25, pp. 1001310019, 2001.

[7] P. Heikkilä and A. Harlin, "Parameter study of electrospinning of polyamide-6," European Polymer Journal, vol. 44, no. 10, pp. 3067-3079, 2008.

[8] Y. T. Jia, J. Gong X, and H. Gu, "Fabrication and characterization of poly (vinyl alcohol)/chitosan blend nanofibers produced by electrospinning method," Carbohydrate Polymers, vol. 67, no. 3, pp. 403-409, 2007.

[9] J. Bai, Y. X. Li, S. T. Yang et al., "A simple and effective route for the preparation of poly(vinylalcohol) (PVA) nanofibers containing gold nanoparticles by electrospinning method," Solid State Communications, vol. 141, no. 5, pp. 292-295, 2007. 

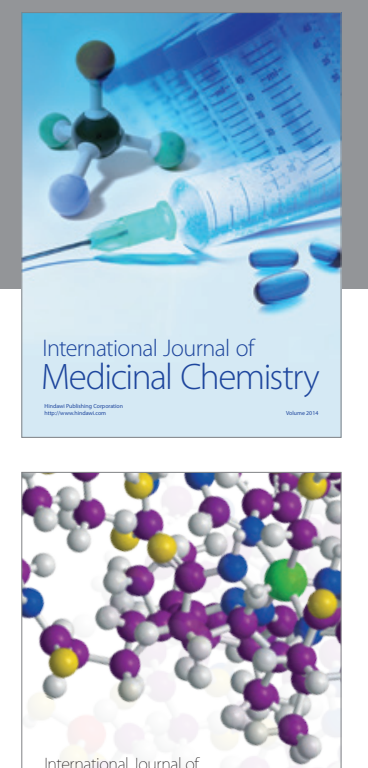

\section{Carbohydrate} Chemistry

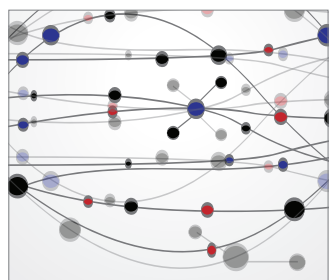

The Scientific World Journal
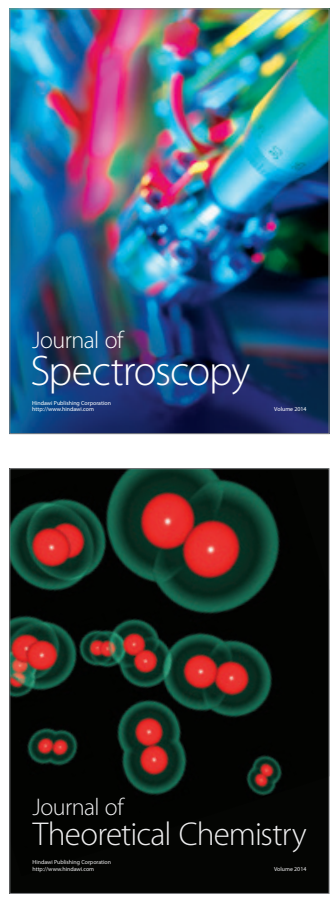
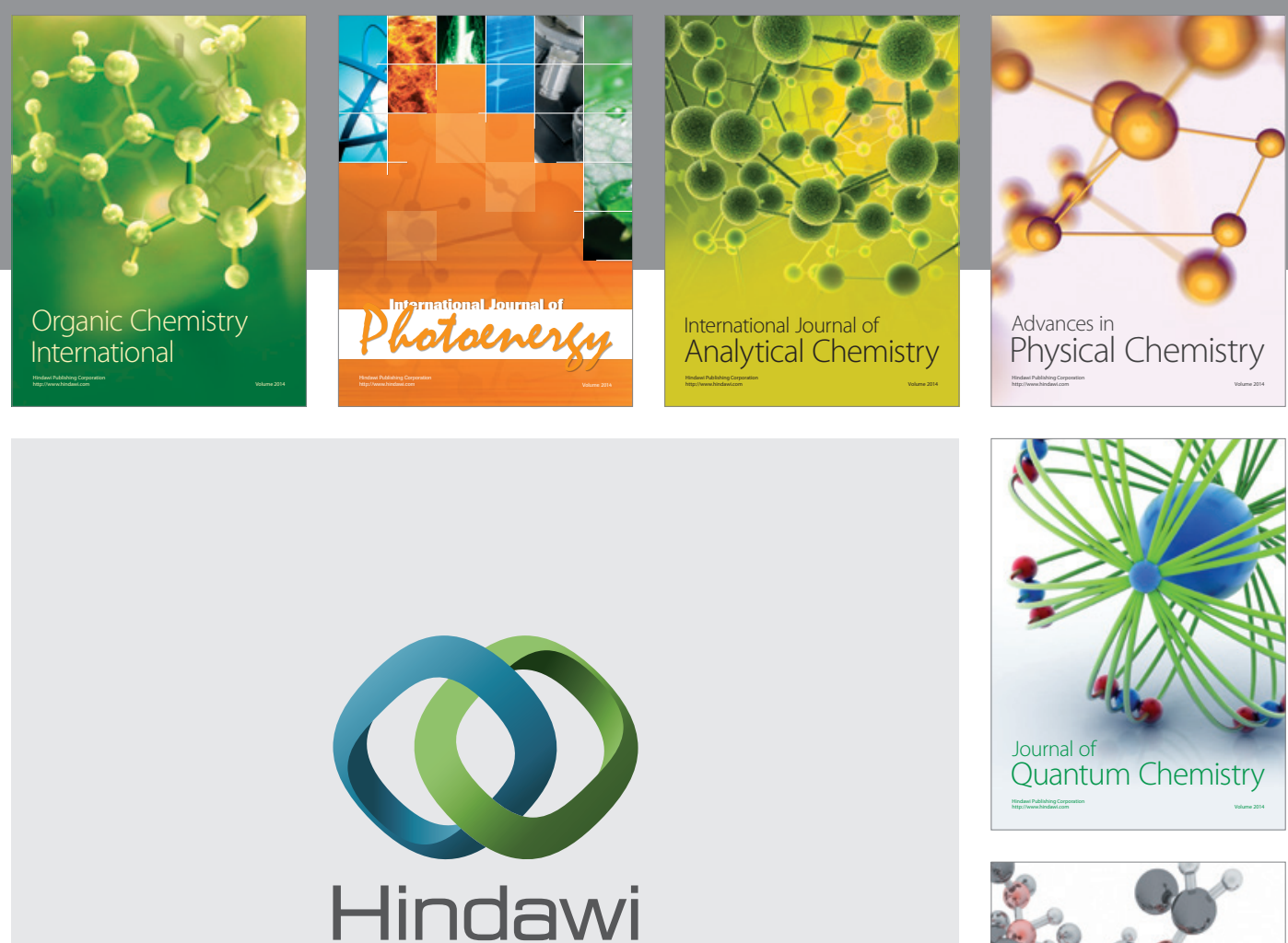

Submit your manuscripts at

http://www.hindawi.com

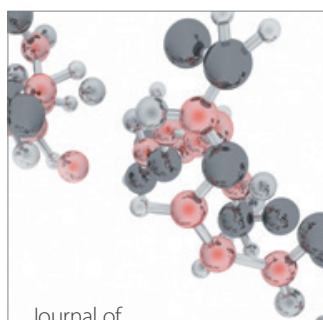

Analytical Methods

in Chemistry

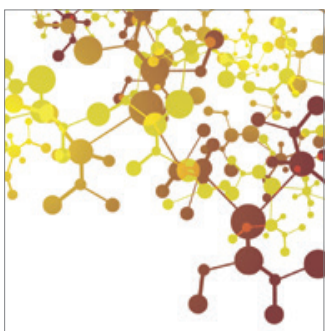

Journal of

Applied Chemistry

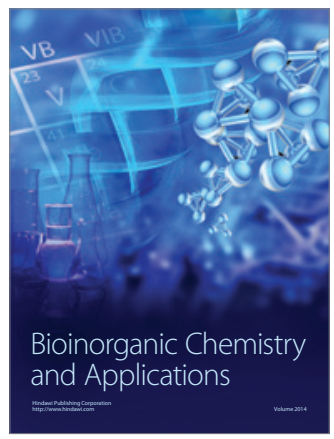

Inorganic Chemistry
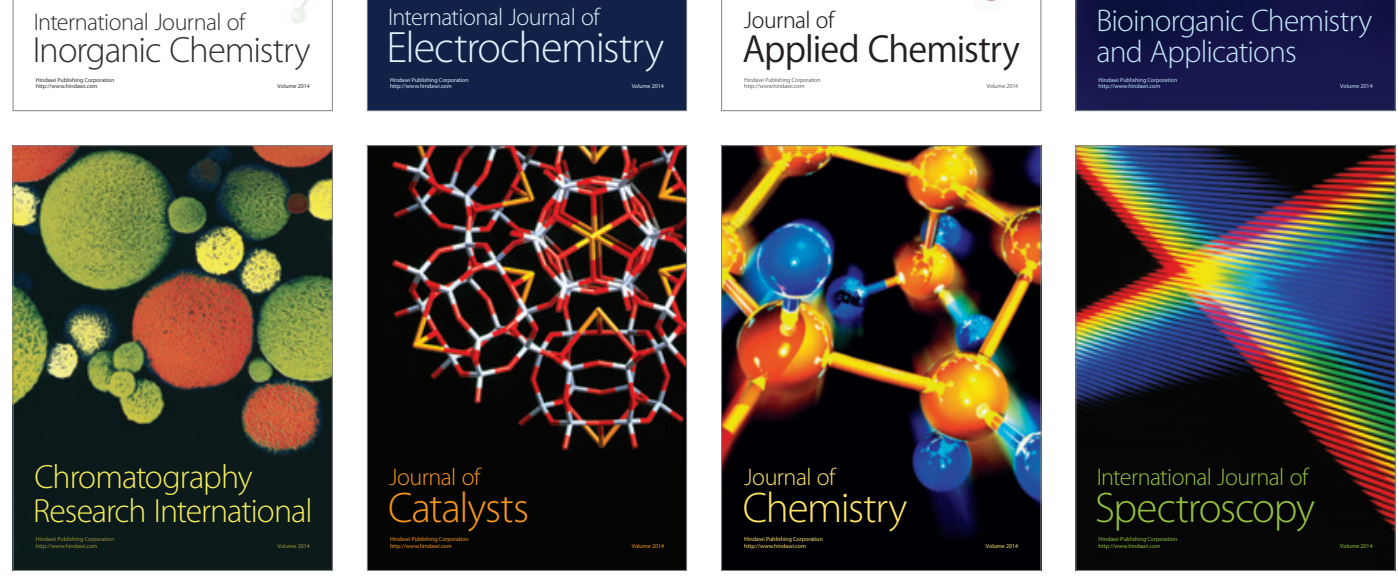